\title{
Localized Resectable Adult Hepatocellular Carcinoma
}

National Cancer Institute

\section{Source}

National Cancer Institute. Localized Resectable Adult Hepatocellular Carcinoma. NCI

Thesaurus. Code C9064.

A localized hepatocellular carcinoma that occurs during adulthood and it is amenable to surgical resection. 